\title{
DIAGNÓSTICO DE GESTÃO DO CONHECIMENTO COMO MECANISMO PARA CRIAÇÃO DE VALOR: UM ESTUDO EXPLORATÓRIO NO SEBRAE-PB
}

\section{DIAGNOSTIC OF KNOWLEDGE MANAGEMENT AS A MECHANISM FOR CREATING VALUE: AN EXPLORATORY STUDY IN SEBRAE-PB}

\author{
Ivani Costa $^{1}$; Ana Cecília Feitosa de Vasconcelos ${ }^{2}$; Gesinaldo Ataíde Cândido ${ }^{3}$ \\ ${ }^{1}$ SEBRAE - João Pessoa- Brasil \\ ivani@sebraepb.com.br \\ ${ }^{1}$ Universidade Federal da Paraíba - UFPB - João Pessoa- Brasil \\ acvasconcelos@gmail.com \\ ${ }^{3}$ Universidade Federal de Campina Grande - UFCG - Campina Grande- Brasil \\ gacandido@uol.com.br
}

\begin{abstract}
Resumo
A complexidade e a incerteza do atual ambiente de negócios têm exigido das organizações a adoção de instrumentos capazes de gerar vantagem competitiva de forma sustentável. Um desses instrumentos envolve a utilização das práticas de gestão do conhecimento, a partir das práticas de disseminação e compartilhamento da informação e do conhecimento. Para sua viabilização $e$ entendimento, diversos estudos foram realizados e resultaram em modelos e metodologias específicas para sua viabilização. Dentre a diversidade de tais modelos e metodologias existentes, destaca-se o proposto por Bukowitz e Williams (2002), o qual se refere a um modelo denominado de Diagnóstico de Gestão do Conhecimento (DGC), o qual permite realizar uma análise da informação e do conhecimento em nível tático e estratégico em organizações. Nesse sentido, o objetivo deste artigo é realizar um diagnóstico de gestão do conhecimento no SEBRAE-PB a partir da aplicação do referido modelo. A pesquisa caracteriza-se como exploratória e descritiva e foi conduzida sob a forma de um estudo de caso. Os resultados apontam que a organização apresenta disparidade entre os níveis tático e estratégico no que tange a informação e o conhecimento como recursos que criam valor para a organização.
\end{abstract}

Palavras-chave: Gestão; Conhecimento; Valor.

\section{Introdução}

O atual ambiente dos negócios é pautado por uma série de novas demandas que impulsionam as organizações a buscarem elementos capazes de gerar vantagem competitiva e que proporcionem condições para o sucesso da organização.

Essas novas demandas têm como cenário uma competitividade acirrada onde a continuidade dos negócios está centrada na estratégica gestão dos recursos das empresas. Assim, o que 
anteriormente parecia conferir às organizações fonte de vantagem competitiva, abre espaço para a crescente importância atribuída ao conhecimento, onde a base para o diferencial está vinculada à capacidade das organizações se reinventarem continuamente e de desenvolverem suas competências essenciais.

Cada vez mais, o conhecimento é entendido e percebido pelas organizações como fonte geradora de valor, principalmente quando a sua utilização está atrelada ao desenvolvimento de novas estratégias. Para conseguirem competir no mercado global, as empresas devem fazer de seus produtos e serviços um agregado de idéias, o que pode ser obtido a partir do conhecimento que é parte integrante dos processos da empresa.

Nesse sentido, a Gestão do Conhecimento (GC) vêm ganhando força nas organizações, se apresentando como um instrumento capaz de viabilizar melhor interação com o fluxo de informações existentes na rotina das organizações, bem como estimular o aprendizado organizacional. Embora seja uma prática recente, a Gestão do Conhecimento é uma ferramenta estratégica que busca captar, criar e utilizar um recurso intangível: o conhecimento, cuja propriedade deixa de ser de alguns privilegiados e passa a se constituir como uma ferramenta de negócio comum a todos os profissionais da organização.

Sendo assim, o mapeamento dos caminhos utilizando técnicas didáticas que permita a realização de ligações entre a teoria e as ações da GC, constitui um importante alicerce, pois apresenta para a empresa o modo como ela funciona, como são realizadas as suas operações, seus negócios e suas atividades e, principalmente, qual o caminho que as informações e o conhecimento devem percorrer, permitindo que a empresa tenha noção de suas potencialidades e possam reinventar novos caminhos.

Com base na ausência de metodologias que permitissem aos gestores a conquista de melhorias no desempenho da gestão do conhecimento, Bukowitz e Williams (2002) propuseram o modelo denominado Diagnóstico de Gestão do Conhecimento (DGC), o qual possibilita a análise da gestão do conhecimento nas organizações por meio da avaliação dos processos tático e estratégico. Dessa forma, para aplicação desse diagnóstico escolheu-se o SEBRAE-PB por esta se caracterizar em uma empresa que tem como principal recurso o conhecimento.

Diante do exposto, este artigo tem como objetivo realizar um diagnóstico da gestão do conhecimento no SEBRAE-PB, a partir do modelo proposto por Bukowitz e Williams (2002). Para a consecução deste, optou-se por uma pesquisa exploratória e quantitativa-descritiva e conduzida sob a forma de estudo de caso, onde foram empregadas as técnicas de coleta de dados a documentação direta através de aplicação de questionários elaborados com base no modelo utilizado. 
Além desta parte introdutória, o artigo explora no referencial teórico a perspectiva conceitual acerca da GC e o modelo proposto por Bukowitz e Williams (2002), explicitando os processos e seções que o constituem. Em seguida estão apresentados os procedimentos metodológicos, a discussão dos resultados, e por fim as considerações finais.

\section{Fundamentos Teóricos}

\subsection{Gestão do Conhecimento: perspectiva conceitual}

O conhecimento é nos dias atuais um dos fatores principais que fazem a diferença nas organizações de sucesso. Proporcionar as condições ideais para que ele possa ser gerado, aproveitado e mantido nas empresas é um dos grandes, senão o maior desafio a ser enfrentado por todos aqueles que direta ou indiretamente comandam os destinos das empresas que representam.

Para Davenport (1988), conhecimento é definido como uma mistura fluida de experiência condensada, valores, informação contextual e insight experimentado, a qual proporciona uma estrutura para a avaliação e incorporação de novas experiências e informações. Para o referido autor, o que faz as organizações funcionarem é o conhecimento, e que a postura das pessoas na organização precisa estar focada na incorporação do conhecimento como um ativo corporativo e há a necessidade de geri-lo e cercá-lo do mesmo cuidado dedicado à obtenção de valor de outros ativos.

Assim, a gestão do conhecimento se mostra como um conjunto de técnicas e ferramentas que permitem identificar, analisar e administrar, de forma estratégica e sistêmica, o ativo intelectual da empresa e seus processos associados. Segundo uma abordagem organizacional mais sistêmica, a gestão do conhecimento compreende o planejamento, a execução e o controle de ações voltadas para desenvolver o conhecimento da empresa e seus processos correspondentes, tendo em vista a excelência empresarial e a criação de vantagens competitivas sustentáveis.

Nesta perspectiva, existem várias formas de abordagens conceituais para a gestão do conhecimento, dentre elas as propostas de Wiig (1993), Leornard-Barton (1995), Nonaka e Takeuchi (1997) e Edvinson e Malone (1998).

A gestão do conhecimento até hoje não é uma unanimidade entre os teóricos e muito menos entre as empresas. Muitos são os autores que estudam esse tema e várias são as abordagens conceituais, as quais algumas se destacam e podem ser observadas no Quadro 01 abaixo. 
Quadro 1 - Evolução da literatura científica relacionada à gestão do conhecimento

\begin{tabular}{|c|c|c|}
\hline ÉPOCA & AUTOR & FOCO E TERMOS USADOS \\
\hline \multirow{2}{*}{$\begin{array}{c}\text { Década } \\
\text { de } 80\end{array}$} & Porter & Conhecimento estratégico \\
\hline & Nonaka e Takeuchi & Compartilhamento de conhecimentos \\
\hline \multirow{13}{*}{$\begin{array}{c}\text { Década } \\
\text { de } 90\end{array}$} & Drucker & Sociedade do conhecimento \\
\hline & Senge & $5^{\text {a }}$ disciplina: pensamento sistêmico \\
\hline & Quinn & Inteligência organizacional \\
\hline & Lipnack e Stamps & Networking \\
\hline & Leonard-Barton & Aptidões estratégicas/ Conhecimento como inovação \\
\hline & Nonaka e Takeuchi & Teoria da criação do conhecimento organizacional \\
\hline & Wigg & Métodos GC/Gerencia do conhecimento \\
\hline & Sveiby & Ativos intangíveis \\
\hline & Stewart & Capital humano, capital estrutural e capital cliente \\
\hline & Edvinsson e Malone & Capital humano, capital estrutural, capital cliente e capital organização \\
\hline & Davenport e Prusak & Ecologia da informação. Prática do conhecimento \\
\hline & Rowley & Definir gestão do conhecimento \\
\hline & Choo & Organização do conhecimento \\
\hline \multirow{8}{*}{$\begin{array}{l}\text { A partir } \\
\text { dos anos } \\
2000\end{array}$} & Amidon & Conhecimento e inovação \\
\hline & $\begin{array}{l}\text { Von Krogh, Ichijo e } \\
\text { Nonaka }\end{array}$ & Consolidação da teoria do conhecimento organizacional \\
\hline & Terra & Práticas gerenciais no processo de gestão do conhecimento \\
\hline & $\begin{array}{l}\text { Shin, Holden e } \\
\text { Schmit }\end{array}$ & Fluxo de conhecimento e sistemas de gestão do conhecimento \\
\hline & Stollenwerk & Modelo genérico de gestão do conhecimento \\
\hline & Bukowitz e Willians & Diagnóstico de gestão do conhecimento \\
\hline & $\begin{array}{l}\text { Probst, Raub, e } \\
\text { Romhardt }\end{array}$ & $\begin{array}{l}\text { Aplicação de gestão do conhecimento com base na abordagem de } \\
\text { "elementos construtivos" }\end{array}$ \\
\hline & $\begin{array}{l}\text { Pesquisadores } \\
\text { diversos, nacionais e } \\
\text { estrangeiros. }\end{array}$ & $\begin{array}{l}\text { Consolidação de conceitos, discussão interdisciplinar, discussão } \\
\text { interdisciplinar, difusão de conhecimento, estudos de casos de } \\
\text { inteligência organizacional e GC }\end{array}$ \\
\hline
\end{tabular}

Fonte: Krücken-Pereira, Costa e Bolzan (2002, p. 52)

De acordo com o explicitado no Quadro 01, pode-se perceber a evolução a qual a gestão do conhecimento alcançou nas últimas décadas e que permitiram entender este tema como algo imprescindível ao sucesso das organizações.

Conforme esclarece Stewart (2002), Gestão do Conhecimento na esfera de uma organização é identificar o que se sabe, captar e organizar esse conhecimento e utilizá-lo de forma que gerem retornos satisfatórios para a organização.

Para Miskie (1996), definir a gestão do conhecimento como uma abordagem estratégica, torna-se necessário fazer uma relação do conhecimento do indivíduo com os conhecimentos organizacionais, que possa produzir um incremento na capacidade de ação do indivíduo e, consequentemente, da organização.

Nesse sentido, a gestão do conhecimento é um processo dinâmico e cíclico que envolve todos os processos da organização, procurando mapear os conhecimentos da organização que direcionados pela sua estratégia, buscam um melhor desempenho organizacional.

Ao identificar os seus conhecimentos, a organização busca adquirir os conhecimentos internos e externos, considerados relevantes para a organização, possibilitando novas formas de desenvolver e criar novos conhecimentos. Compartilhando todos esses conhecimentos e expertises 
para toda a organização e tornando-os utilizáveis, a gestão do conhecimento aumenta o valor organizacional e ajuda a alcançar os seus objetivos (BUKOWITZ; WILLIAMS, 2002).

Com base no exposto e no desenvolvimento a que a gestão do conhecimento alcançou no campo teórico, permitiu a percepção e a necessidade elaboração de modelos práticos que possibilitassem a sua sistematização de modo a proporcionar maiores retornos estratégicos. Nesta perspectiva, alguns modelos foram elaborados com e estão explicitados do tópico a seguir.

\subsection{Modelos de Gestão do Conhecimento}

Por ser um ativo de difícil mensuração, o conhecimento das organizações, muitas vezes não é alinhado aos objetivos dessas e tampouco utilizado de forma estratégica. A partir dessa percepção e da necessidade de reverter esse cenário e proporcionar às pessoas e às organizações melhores formas de utilização desse recurso tão valioso, muitos pesquisados elaboraram modelos de gestão do conhecimento, específicos para sua aplicação.

Quadro 02 - Modelos de Gestão do Conhecimento

\begin{tabular}{|c|c|}
\hline AUTORES & DESCRIÇÃO \\
\hline Sveiby (1998) & $\begin{array}{l}\text { Traz um modelo que possibilite calcular o valor do intangível de uma } \\
\text { organização, a partir de indicadores existentes em três grupos: (1) estrutura } \\
\text { externa, relacionado com o meio e agentes externos; (2) estrutura interna, } \\
\text { relacionado a estrutura e organização interna da organização e; (3) estrutura de } \\
\text { competências dos funcionários, relacionado a capacidade de ação, adaptação e } \\
\text { aprendizagem. }\end{array}$ \\
\hline $\begin{array}{c}\text { Edvinsson; Malone } \\
\text { (1998) }\end{array}$ & $\begin{array}{l}\text { O modelo Skandia Navigator é criado no intuito de identificar e/ou melhorar o } \\
\text { capital intelectual organizacional. Para eles, o capital de mercado e financeiro que } \\
\text { representam a empresa visívelmente é suportada pelo capital intelectual invisível } \\
\text { existente, o qual é gerado a partir das inter-relações entre o capital humano, o } \\
\text { capital organizacional e o capital do cliente. Para mensurar tais aspectos } \\
\text { intangíveis, foi desenvolvido um esquema a partir de alguns indicadores-chave, } \\
\text { quais sejam: foco financeiro, foco no cliente, foco humano, foco no processo, foco } \\
\text { no desenvolvimento e na renovação. Essas são áreas nas quais uma empresa deve } \\
\text { focalizar sua atenção, pois, desses focos provém o valor de seu Capital Intelectual } \\
\text { no âmbito de seu ambiente competitivo. Neste sentido, para que tal recurso seja } \\
\text { estratégico é preciso expandir a expertise, encorajar a inovação e exercitar a } \\
\text { integridade. }\end{array}$ \\
\hline $\begin{array}{c}\text { Davenport; Prusak } \\
\text { (1998) }\end{array}$ & $\begin{array}{l}\text { Para os autores, uma empresa pode "gerar" novos conhecimentos por aquisição ou } \\
\text { por desenvolvimento. A gestão do conhecimento é o conjunto de quatro grandes } \\
\text { etapas: (1) a geração de conhecimento de forma consciente e intencional - por } \\
\text { aquisição, por recursos dirigidos, unidades ou grupos formados com finalidade } \\
\text { específica; por fusão; por adaptação e por rede do conhecimento); (2) a } \\
\text { codificação e coordenação de conhecimento - através da elaboração de um mapa } \\
\text { do conhecimento e da utilização de modelos de conhecimento, de recursos } \\
\text { multimídia e hipertextos de intranets, de narrativas e histórias, de sistemas } \\
\text { especialistas e de inteligência artificial, e de patentes e relatórios, em menor escala } \\
\text { e em função das limitações existentes; (3) a transferência de conhecimento - com } \\
\text { o apoio de ferramentas de tecnologia de informação e observação da influência da } \\
\text { cultura organizacional e da definição do tipo de conhecimento que se quer } \\
\text { transferir; (4) a utilização - de modo que o conhecimento transferido provoque } \\
\text { mudança. }\end{array}$ \\
\hline
\end{tabular}




\begin{tabular}{|c|c|}
\hline Choo (1998) & $\begin{array}{l}\text { O modelo da organização do conhecimento (knowing organization) propõe o ciclo } \\
\text { que aborda o uso estratégico da informação nos processos de construção de } \\
\text { sentido (sense making), criação de conhecimento e tomada de decisão. Através da } \\
\text { interação dessa rede de processos, os quais estão socialmente distribuídas por } \\
\text { muitos níveis e funções da instituição, a organização constrói significados comuns } \\
\text { sobre sua identidade e sua atividade, gerando o conhecimento organizacional. }\end{array}$ \\
\hline $\begin{array}{c}\text { Leonard-Barton } \\
\text { (1998) }\end{array}$ & $\begin{array}{l}\text { Relaciona construção do conhecimento a quatro atividades: (1) aquelas focadas na } \\
\text { busca por soluções criativas de forma compartilhada; (2) atividades concentradas } \\
\text { na implementação e integração de novas metodologias e ferramentas nos } \\
\text { processos internos; (3) atividades focadas na prática de experimentos, a partir de } \\
\text { protótipos e projetos piloto para desenvolvimento de competências para o futuro } \\
\text { e; (4) atividades concentradas na absorção de know-how de fontes externas. Essas } \\
\text { atividades, são influenciadas, por sua vez, por competências essenciais (apoiadas } \\
\text { por mecanismos tecnológicos) e se transformam em vantagens competitivas para a } \\
\text { organização. As competências identificadas estão contidas: nas qualificações, } \\
\text { conhecimentos e habilidades dos indivíduos; nos sistemas físicos; nos sistemas } \\
\text { gerenciais; e nos valores ou nas normas da organização. }\end{array}$ \\
\hline Terra (2001) & $\begin{array}{l}\text { Apresenta uma visão abrangente, baseado em sete dimensões da GC: (1) visão e } \\
\text { estratégia da alta administração; (2) cultura organizacional; (3) estrutura } \\
\text { organizacional (4) políticas de recursos humanos (5) Sistemas de Informações; (6) } \\
\text { mensuração de resultados; (7) aprendizado com o ambiente. Para ele, o } \\
\text { significado de gestão do conhecimento é o modo pelo qual os conhecimentos são } \\
\text { gerados, difundidos, apropriados e aplicados por pessoas e por empresas ou outras } \\
\text { organizações. Isto implica na adoção de práticas gerenciais compatíveis com os } \\
\text { processos de criação e de aprendizagem individual; com a coordenação sistêmica } \\
\text { de esforços nos planos organizacionais e individuais, estratégico e tático; e com } \\
\text { normas formais e informais. }\end{array}$ \\
\hline $\begin{array}{c}\text { Nonaka; Takeuchi } \\
\text { (1997) }\end{array}$ & $\begin{array}{l}\text { Focam a criação do conhecimento, que é obtida a partir da conversão do } \\
\text { conhecimento tácito em conhecimento explícito (através de um processo de } \\
\text { informação) e vice-versa. Esse é um processo contínuo e dinâmico, na forma de } \\
\text { espiral, contemplando duas dimensões: (1) a dimensão epistemológica, a qual } \\
\text { converte conhecimento tácito em conhecimento explícito a partir das práticas de } \\
\text { combinação (explícito p/ explícito), internalização (explícito p/ tácito) e } \\
\text { socialização (tácito p/ tácito), externalização (tácito p/ explícito); (2) a dimensão } \\
\text { ontológica, que transfere o conhecimento individual para o grupo, que por sua vez } \\
\text { passa para a organização e para outras organizações. }\end{array}$ \\
\hline Stewart (1998) & $\begin{array}{l}\text { Sugere um gráfico circular (Navegador do Capital Intelectual), em forma de tela } \\
\text { de radar, o qual irá monitorar indicadores simultaneamente, quais sejam: índice de } \\
\text { rotatividade de trabalhadores do conhecimento, atitude dos funcionários, custo de } \\
\text { substituição de banco de dados, satisfação do cliente e valor da marca. }\end{array}$ \\
\hline Wiig (1999) & $\begin{array}{l}\text { afirma que, na prática, a gestão do conhecimento, estrutura suas atividades e } \\
\text { prioridades por meio do ele chamou de "Ciclo da Evolução do Conhecimento } \\
\text { Organizacional", composto por cinco estágios: criação do conhecimento, } \\
\text { aquisição do conhecimento, refinamento do conhecimento, disponibilização e } \\
\text { distribuição do conhecimento e, aplicação do conhecimento. }\end{array}$ \\
\hline Probst et. al (2002) & $\begin{array}{l}\text { Apresentam uma estrutura integrada com processos essenciais de gestão do } \\
\text { conhecimento, a saber: identificação do conhecimento, aquisição do } \\
\text { conhecimento, desenvolvimento do conhecimento, compartilhamento e } \\
\text { distribuição do conhecimento, utilização do conhecimento e retenção do } \\
\text { conhecimento. Tais processos geram um quadro amplo dos problemas } \\
\text { operacionais que podem surgir ao considerar o conhecimento como um recurso. A } \\
\text { sugestão dada pelos autores é que as intervenções operacionais estejam sob uma } \\
\text { estrutura de coordenação que lhe dê orientação. Tal orientação é apoiada pelas } \\
\text { metas de conhecimento e sua avaliação. }\end{array}$ \\
\hline $\begin{array}{c}\text { Bukowitz; Williams } \\
\text { (2002) }\end{array}$ & $\begin{array}{l}\text { Apresentam uma metodologia que realiza um diagnóstico da gestão do } \\
\text { conhecimento nas organizações, compreendendo o processo tático e o estratégico. } \\
\text { Esse diagnóstico apresenta-se dividido em sete seções, as quais quatro (Obtenha, } \\
\text { Utilize, Aprenda, Contribua) correspondem ao processo tático e três ao processo } \\
\text { estratégico (Avalie, Construa/Mantenha, Despoje). Esta proposta é um } \\
\text { instrumento qualitativo e tem o propósito de provocar a reflexão dos assuntos e } \\
\text { preocupações que cercam a GC nas organizações. }\end{array}$ \\
\hline
\end{tabular}

Fonte: Adaptado de Caldas (2008) 
A partir da explicitação dos modelos exibidos no Quadro 02, escolheu-se o modelo proposto por Bukowitz e Williams (2002), uma vez que este se configura em um instrumento subjetivo que pode desencadear medidas quantitativas e objetivas que proporcionará uma avaliação para criar medidas de acompanhamento do desempenho de um programa de Gestão do Conhecimento. Tal modelo poderá ser compreendido de melhor forma a partir do tópico a seguir.

\subsection{Diagnóstico de Gestão do Conhecimento: o modelo de Bukowitz e Williams (2002)}

A gestão do conhecimento é um campo em evolução e todos os dias são gerados novas compreensões à medida que as organizações têm novas experiências, aprendem e avançam. Entretanto, mesmo com tantas abordagens diferenciadas acerca da GC, percebe-se a necessidade da estruturação desta como uma forma de melhor entender, potencializar e utilizar o conhecimento existente nas organizações.

A partir dessa necessidade as autoras Bukowitz e Williams (2002) propuseram o Diagnóstico de Gestão do Conhecimento (DGC), o qual é fundamentado em um manual de estruturação de processos da gestão do conhecimento partindo da avaliação inicial da situação da empresa e definindo conceitos importantes na implementação de práticas que geram e mantém o conhecimento.

O diagnóstico de gestão do conhecimento (DGC) é dividido em dois processos (tático e estratégico), os quais são compostos por sete seções, como demonstrado na Figura 01 abaixo.

Figura 1 - Estruturação do processo de gestão do conhecimento

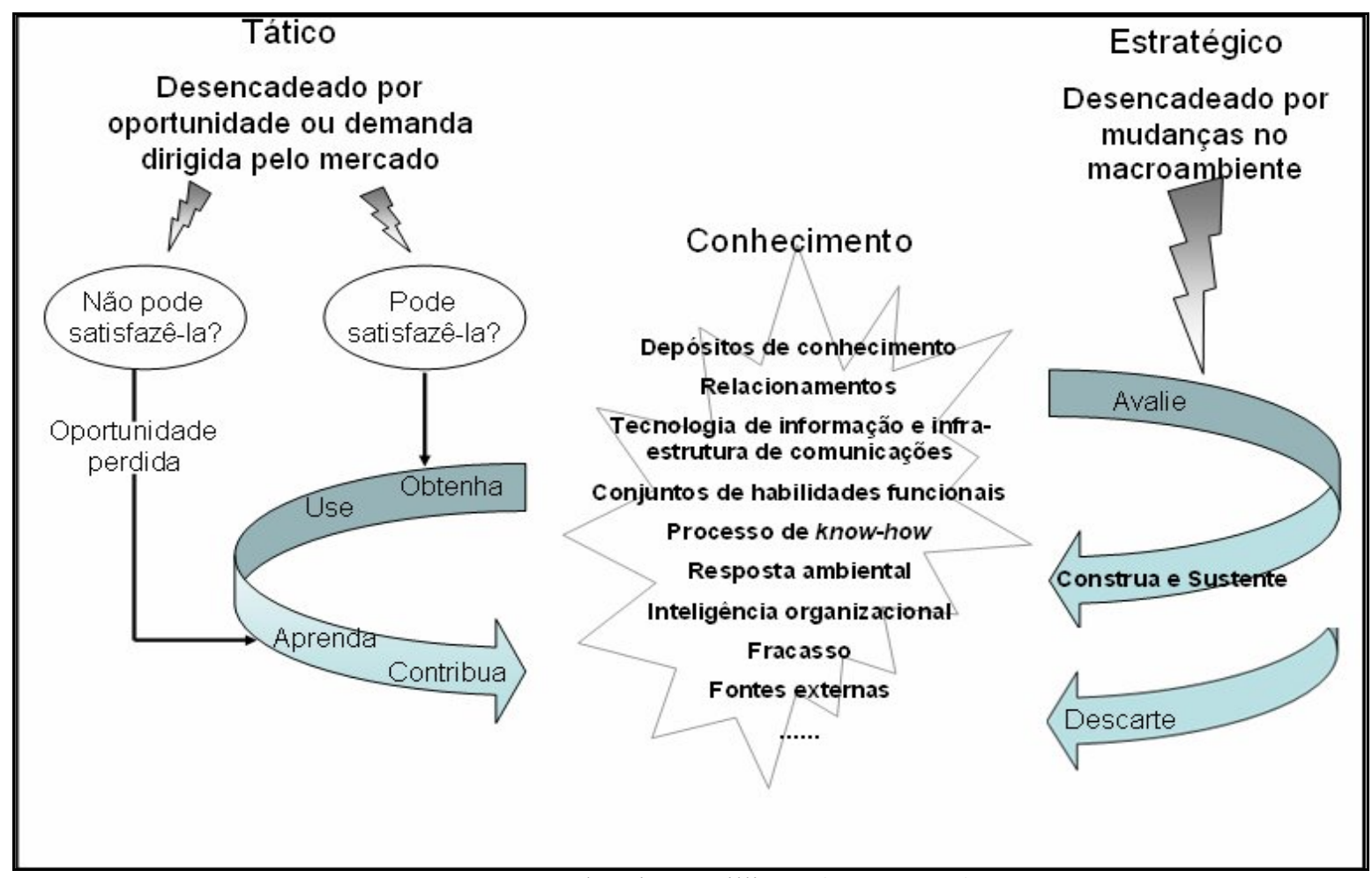

Fonte: Bukowitz e Williams (2002, p. 24). 
Cada seção que compõe os processos do Diagnóstico de Gestão do Conhecimento (DGC) é caracterizada, segundo suas autoras, por um conjunto de desafios que precisam ser diagnosticados pelas organizações que pretendem promover ou potencializar a gestão do conhecimento.

Em seguida, para melhor entendimento, segue especificadamente as seções e os desafios que compõem cada processo do DGC.

\section{I) PROCESSO TÁTICO}

Esse processo refere-se à utilização do conhecimento no dia-a-dia para responder às demandas ou às oportunidades do mercado. É composto por quatro passos que tratam da forma como as pessoas lidam diariamente com o conhecimento utilizando-o como ferramenta para criar valor, aprender e repassar o que aprenderam para que os demais que compõem a empresa possam também contribuir com a geração de valor.

- SEÇÃO OBTENHA: é o primeiro passo do processo de gestão do conhecimento e está vinculado à descrição da necessidade de informação, bem como saber solicitar, entender, comunicar e capturar a informação.

- SEÇÃO UTILIZE: ocorre a combinação de informação de formas novas e interessantes para promover a inovação organizacional. Para que isto ocorra da melhor maneira possível é indispensável derrubar as barreiras estruturais, sejam hierárquicas ou físicas, que impedem que o conhecimento obtido se dissemine pela organização.

- SEÇÃO APRENDA: trata da aprendizagem individual e organizacional, reconhecendo formalmente o valor da educação aplicada, identificando as formas de aprendizagem no cotidiano e integrando os mecanismos de reflexão no hábito do trabalho.

- SEÇÃO CONTRIBUA: diz respeito ao compartilhamento do conhecimento, ou seja, transferir o conhecimento individual para a organização, promovendo a compreensão e o respeito pelo valor do conhecimento compartilhado.

Os desafios que caracterizam o processo tático estão explicitados no Quadro 03 abaixo.

\begin{tabular}{|l|c|c|}
\multicolumn{1}{|c|}{ Quadro 03 - Desafios do processo Tático } \\
\hline SEÇãO & \multicolumn{1}{c|}{ DESAFIOS } \\
\hline & - & Entender e comunicar o uso pretendido da informação; \\
& - & Direcionar as solicitações de informação adequadamente; \\
& - & Utilizar as comunidades de prática para lançar um raio de luz sobre o \\
& & conhecimento organizacional; \\
OBTENHA & - & Equilibrar as tecnologias "de empurrar" e "de puxar"; \\
& - & Envolver o usuário na criação dos instrumentos de navegação e captura; \\
& - & Criar um novo papel: o gestor de conhecimento; \\
& - & Ptilizar especialistas como filtros de informação; \\
& & individualmente; \\
& - & Criar estruturas e processos que promovam a reutilização do conhecimento. \\
\hline
\end{tabular}




\begin{tabular}{|c|c|c|}
\hline UTILIZE & & $\begin{array}{l}\text { Formatar a estrutura organizacional para melhorar as comunicações e os fluxos de } \\
\text { conhecimento; } \\
\text { Planejar o ambiente físico de modo que as idéias se cruzem e se fertilizem; } \\
\text { Tratar a informação como um recurso aberto, que flui livremente para todos os } \\
\text { cantos da organização; } \\
\text { Colaborar com todas as comunidades envolvidas rotineiramente; } \\
\text { Valorizar as contribuições de todos na organização; }\end{array}$ \\
\hline APRENDA & & $\begin{array}{l}\text { Retratar a complexidade dos sistemas humanos; } \\
\text { Envolver mente e corpo para vincular os temas "leves" à estratégia; } \\
\text { Promover o principio do prazer no trabalho; } \\
\text { Integrar os mecanismos de reflexão no hábito do trabalho; } \\
\text { Captar os benefícios dos erros, fracassos e discordâncias; } \\
\text { Cultivar e arte de aprender fazendo. }\end{array}$ \\
\hline CONTRIBUA & & $\begin{array}{l}\text { Remover as barreiras do compartilhamento } \\
\text { Vincular a contribuição com a oportunidade e o avanço } \\
\text { Reter benefícios dos que não contribuem } \\
\text { Encontrar pontos de benefícios mútuos } \\
\text { Dar tempo e espaço para que os empregados contribuam com o melhor do } \\
\text { trabalho deles; } \\
\text { Criar funções de dedicação exclusiva que apóiem o processo de contribuição } \\
\text { Apoiar a transferência de conhecimento implícito; } \\
\text { Tecer uma rede organizacional } \\
\text { Promover um contrato de reciprocidade } \\
\text { Criar políticas explicitas para promover a propriedade } \\
\text { Utilizar a publicação individual para promover a propriedade } \\
\text { Valorizar os laços de confiança }\end{array}$ \\
\hline
\end{tabular}

Fonte: Adaptado de Bukowitz e Williams (2002)

De modo semelhante à explicitação do processo tático do DGC, segue o processo estratégico o qual visa alinhar a estratégia de conhecimento da organização com a estratégia geral de negócios.

\section{II) PROCESSO ESTRATÉGico}

Essa fase do DGC se refere a um processo de longo prazo da combinação entre o intelectual e as exigências estratégicas, ou seja, o objetivo é o alinhamento da estratégia do conhecimento da organização com a estratégia geral do negócio, enfatizando o papel dos grupos e das lideranças organizacionais específicas.

- SEÇÃO AVALIE: direciona-se à identificação das novas formas de capital organizacional e a visualização das estruturas que guiam as práticas de gestão do conhecimento.

- SEÇÃO CONSTRUA / MANTENHA: busca assegurar que o conhecimento mantenha a organização viável e competitiva por meio dos seus futuros ativos do conhecimento, bem como canaliza recursos de maneira que reabasteçam e criem conhecimento.

- SEÇÃO DESPOJE: nesta seção o enfoque não está apenas em descartar, mas também em não adquirir conhecimento que não seja necessário à organização em determinado momento, pois o que deve ser levado em conta é o objetivo específico da organização. 
Os desafios que caracterizam o processo estratégico estão melhor explicitados no Quadro 04 abaixo.

Quadro 04 - Desafios do processo Estratégico

\begin{tabular}{|c|c|}
\hline SEÇÃO & DESAFIOS \\
\hline AVALIE & $\begin{array}{ll}- & \text { Identificar as novas formas de capital organizacional; } \\
\text { - } & \text { Conceber as novas tarefas de gestão; } \\
\text { - } & \text { Visualizar as estruturas que guiam as pratica de gestão do conhecimento; } \\
\text { - } & \text { Fazer experiências com abordagens de avaliação e de calculo para estimar os } \\
& \text { resultados estratégicos; } \\
\text { - } & \text { Comunicar-se com os principais stakeholders. }\end{array}$ \\
\hline $\begin{array}{l}\text { CONSTRUA/ } \\
\text { SUSTENTE }\end{array}$ & 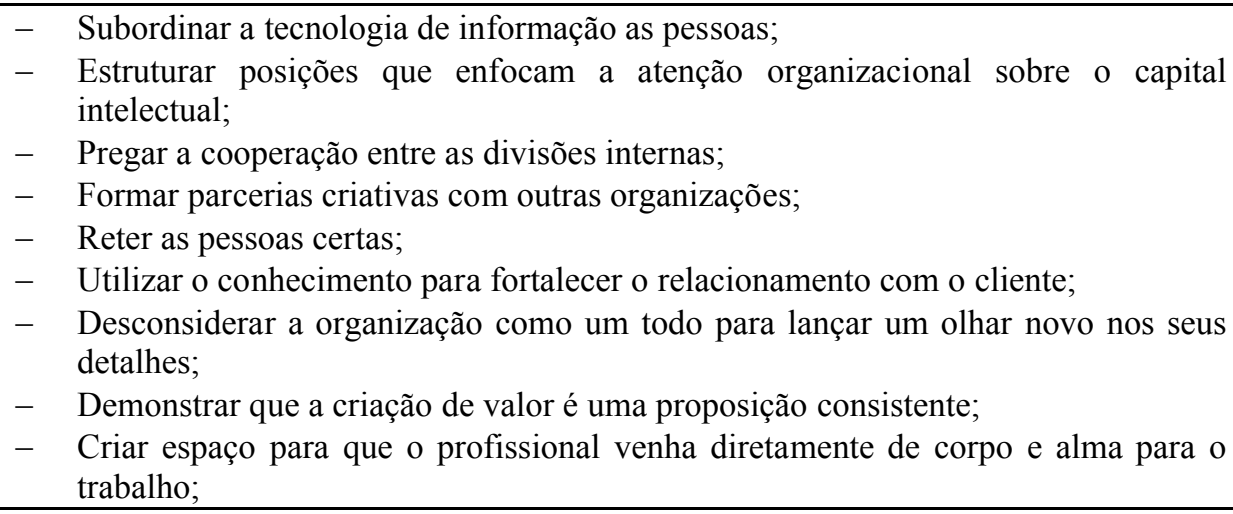 \\
\hline DESPOJE & $\begin{array}{l}\text { - } \text { Reconhecer as formas de conhecimento que podem ser alavancadas e aquelas que } \\
\text { são limitadas; } \\
\text { - Encontrar alternativas para o aproveitamento direto, a fim de fazer experiências } \\
\text { com o conhecimento; } \\
\text { - } \\
\text { Reconhecer e dispensar os verdadeiros drenos de recursos. }\end{array}$ \\
\hline
\end{tabular}

Fonte: Adaptado de Bukowitz e Williams (2002)

A partir do modelo proposto por Bukowitz e Williams (2002), este artigo tem como objetivo diagnosticar a gestão do conhecimento do SEBRAE-PB e sua consolidação pode ser melhor entendida por meio dos procedimentos metodológicos utilizados e da análise dos resultados que se seguem.

\section{Procedimentos Metodológicos}

A pesquisa realizada pode ser caracterizada como exploratória e quantitativa-descritiva e conduzida sob a forma de estudo de caso, a qual objetivou realizar um diagnóstico da gestão do conhecimento no SEBRAE-PB, buscando-se delinear ou analisar características de fatos ou fenômenos com o intuito de fazer com que o pesquisador pudesse ter certo aprofundamento acerca do assunto estudado.

A escolha do SEBRAE-PB deve-se ao fato desta organização ser caracterizada como uma instituição que tem como principal recurso o conhecimento. 
No que se refere às técnicas de pesquisa, foram empregadas a documentação direta através da aplicação de questionário o qual foi elaborado com base nos processos, seções e desafios, propostos no Diagnóstico de Gestão do Conhecimento de Bukowitz e Williams (2002).

A escolha desse modelo para realização deste estudo deveu-se ao fato deste se apresentar como uma forma prática e sistemática para analisar o processo de gestão do conhecimento em uma organização, identificando as potencialidades e as dificuldades nesse processo.

As autoras do modelo utilizado elaboraram o questionário composto por sete seções (Obtenha, Utilize, Aprenda, Contribua, Avalie, Construa/Sustente, Despoje), das quais quatro seções correspondem ao processo tático e três ao processo estratégico. Cada seção é composta por uma série de características, denominadas pelas as autoras de "desafios", que permite um melhor diagnóstico de gestão do conhecimento das organizações.

Para a avaliação dos questionários, Bukowitz e Williams (2002) estabeleceram uma pontuação, onde cada seção avaliada atinge uma valoração máxima de 60 pontos e cada questionário um peso máximo de 420 pontos, uma vez que é constituída de sete seções. A análise de cada seção será realizada com base no resultado da divisão do número de pontuação dada por cada entrevistado por 60 (pontuação total de cada seção), resultando em um percentual que representará a intensidade de cada seção na organização.

Para efetivação deste estudo os questionários foram direcionados às gerências do SEBRAE$\mathrm{PB}$, assim como às pessoas que, de alguma forma, contribuem ou trabalham diretamente com a promoção do conhecimento dentro da referida empresa. Foram direcionados 20 questionários, dos quais houve um retorno de $95 \%$ do total, o que corresponde a 19 questionários.

Com base na explicitação do percurso metodológico utilizado para realização deste artigo, serão enfatizados no tópico seguinte os resultados obtidos quanto ao Diagnóstico de Gestão do Conhecimento no SEBRAE-PB.

\section{Análise dos Resultados}

De acordo com o modelo utilizado proposto por Bukowitz e Williams (2002), é possível diagnosticar de forma sistemática a gestão do conhecimento, analisando em quais fases as organizações se encontram mais focadas no processo de geração e disseminação do conhecimento.

No caso específico deste estudo, o qual teve como foco o SEBRAE-PB, o processo de análise dos dados procurou identificar como a instituição estudada gerencia o conhecimento; como estas bases são utilizadas por seus funcionários; como estes funcionários utilizam a aprendizagem como forma de criar soluções inovadoras e competitivas; como todas as informações utilizadas contribuem para a gestão do conhecimento; de que forma a organização avalia o capital intelectual atual e a necessidade futura e como constrói as bases para que o conhecimento gerado seja mantido 
e torne a organização viável e competitiva, além de entender como a mesma descarta as informações e conhecimentos adquiridos que não mais criam valor para o negócio.

Para cada seção analisada foi calculado o percentual da pontuação possível tomando-se como base o cálculo disponível na ferramenta de Bukowitz e Williams (2002).

A seguir é apresentada tabela com os dados obtidos na coleta de dados:

Tabela 1 - Resultado da pesquisa

\begin{tabular}{lcc}
\hline \multicolumn{1}{c}{ SEÇÃO } & $\begin{array}{c}\text { PONTUAÇÃO TOTAL DA } \\
\text { ETAPA* }\end{array}$ & $\begin{array}{c}\text { PERCENTUAL DA ETAPA } \\
(\%) * *\end{array}$ \\
\hline PROCESSO TÁTICO & 771 & $67,63 \%$ \\
\hline Obtenha & 701 & $61,49 \%$ \\
\hline Utilize & 791 & $69,39 \%$ \\
\hline Aprenda & 533 & $46,75 \%$ \\
\hline Contribua & 471 & \\
\hline PROCESSO ESTRATÉGICO & 736 & $61,32 \%$ \\
\hline Avalie & 561 & $64,56 \%$ \\
\hline Construa/Mantenha & $\mathbf{5 7 , 1 9 \%}$ \\
\hline Despoje & \\
\hline TOTAL & \\
\hline $\begin{array}{l}\text { Fonte: Dados da pesquisa (2007) } \\
\text { (*) Este valor representa o somatório de todos os questionários. } \\
\text { (**) Estes valores representam a média do percentual de todos os questionários. }\end{array}$ \\
\hline
\end{tabular}

Com base na pontuação de cada etapa pôde-se encontrar quais os processos que se apresentam em melhores condições no SEBRAE-PB de acordo com o Diagnóstico de Gestão do Conhecimento.

\section{I) PROCESSO TÁTICO}

\section{- OBTENHA}

Esta etapa apresentou-se com $\mathbf{6 7 , 6 3 \%}$ de intensidade, revelando que de forma moderada, as pessoas conseguem localizar as informações as quais necessitam no momento em que as procuram. Tal fato revela certa capacidade de articular as necessidades de informação, demonstrando que as pessoas têm consciência de quais informações precisam em determinado momento e qual o seu uso pretendido, direcionando as solicitações de informação adequadamente. Entretanto, percebe-se que os indivíduos não documentam e compartilham informações sobre as suas expertises rotineiramente, o que representa um ponto fraco na seção obtenha.

Normalmente, as pessoas da organização em análise sabem onde encontrar os meios que geram o conhecimento, pois a organização disponibiliza sistemas que orientam para tal atividade, entretanto, não aloca recursos para os especialistas que desejam gerenciar o conhecimento. Existe grande acesso aos recursos de TI que intensifica o saber da organização, puxando e empurrando as informações para todos que atuam na organização. Contudo, a organização em questão precisa utilizar melhor essas ferramentas como forma de garimpar o conhecimento acessível, criando 
significado a partir da enorme quantidade de dados disponíveis diariamente. A partir dessa garimpagem e criação de valor, tais informações poderão se tornar um importante instrumento de gestão de conhecimento cada vez mais significativo à medida que estiverem acessíveis a mais membros da organização.

Dessa forma, observa-se que no SEBRAE-PB o processo de obter encontra-se potencializado, embora seja necessário adotar algumas medidas de ação com o intuito de melhorar a intensidade desse processo e alinhá-lo aos objetivos centrais da organização, uma vez que em alguns pontos a organização demonstrou certa distância entre a intenção de promover meios que facilite a obtenção do conhecimento e a sua efetiva realização.

\section{- UTILIZE}

Esta seção apresentou-se com $\mathbf{6 1 , 4 9 \%}$ o que demonstra que a organização em questão incentiva o pensamento livre e encoraja a criatividade e a experimentação. Entretanto, essa liberdade de pensamento e criatividade não está direcionada para todas as pessoas e para todos os níveis, uma vez que nem todas as pessoas têm o poder para opinar ou explicitar uma idéia mesmo acreditando que seria de grande valia para a resolução de determinado problema. A empresa incentiva a criatividade, porém só considera com seriedade as idéias advindas de indivíduos específicos, o que pode acarretar desperdício de idéias brilhantes e até mesmo em desmotivação para geração de novas idéias.

Àquelas idéias que a empresa considera como inovadoras são percebidas como mecanismo gerador de valor para o cliente, o que permite maneiras novas de construir soluções e de tirar mais vantagem das oportunidades.

Com base nesses dados, pode-se afirmar que o SEBRAE-PB tem capacidade de utilizar o conhecimento obtido de forma efetiva e o reverter em criação de valor para o cliente. Porém, tornase necessário que esse processo de geração e utilização de idéias seja percebido como um processo democrático e participativo, a partir da quebra de barreiras estruturais, onde todas as pessoas que compõem a organização possam ter a oportunidade de serem ouvidas e suas idéias consideradas e discutidas como um caminho possível e não como um processo onde poucos podem opinar ou contribuir.

\section{- APRENDA}

De todas as seções, esta foi a que se apresentou com maior intensidade: 69,39\%, o que indica que na organização em análise as pessoas aprendem e contribuem para a base de conhecimento organizacional, pois acreditam que esse passo é fundamental para a realização de objetivos estratégicos. 
$\mathrm{Na}$ empresa em análise, é relevante analisar os erros e os fracassos e refletir sobre as lições resultantes dessas experiências com o objetivo de identificar os pontos que podem ser melhorados e assim, aprender com eles. Contudo, essa busca pela melhoria, não ocorre de forma efetiva, pois quando os erros ocorrem não se tira o devido proveito deles. É necessário que os indivíduos reflitam o tempo todo sobre as experiências adquiridas, sejam elas positivas ou negativas, pois essa é a essência da aprendizagem. De acordo com Bukowitz e Williams (2002) é difícil admitir que os procedimentos dêem errado quando pessoas estão envolvidas. Contudo, quando as organizações vêem erros, fracassos e discordâncias como o berço da inovação e das idéias, elas são capazes de descobrir maneiras de incorporá-los ao modelo de trabalho.

Dessa forma, sugere-se que o SEBRAE-PB estabeleça práticas efetivas que incorporem os erros que ocasionalmente acontecem nas atividades desenvolvidas, entendendo que os colaboradores não são úteis apenas pelo que sabem, mas pelo que continuam a aprender e como esse aprendizado poderá se transformar em retorno, quer seja individual ou organizacional.

\section{- CONTRIBUA}

Os resultados demonstram que na organização em análise, essa seção apresenta-se de forma tímida em relação às demais seções do processo tático, com apenas $\mathbf{4 6 , 7 5 \%}$ de intensidade.

Esse percentual demonstra certa fragilidade no que se refere ao compartilhamento de conhecimento, principalmente, na transferência do conhecimento individual para a organização. Para reverter essa situação é necessário motivar os membros, estabelecendo sistemas de recompensas e removendo as barreiras de compartilhamento, procurando atrelar a contribuição à oportunidade e ao avanço, tanto organizacional quanto individual. $\mathrm{O}$ resultado dessa seção pode ser entendida como reflexo da seção Utilize que, de certa forma, bloqueia a criatividade e a inovação.

Ressalta-se que uma cultura de contribuição não é gerada repentinamente e nem de forma imposta. Para que haja o alinhamento dos interesses individuais com os organizacionais, é imprescindível esclarecer que todos na organização têm algo de valor para contribuir, além de promover a compreensão e o respeito pelo valor do conhecimento compartilhado.

De forma geral, o processo tático do DGC no SEBRAE-PB mostrou-se de forma positiva, uma vez que três das quatro seções se apresentaram com percentuais acima de $50 \%$, embora, alguns pontos específicos dentro de cada seção precisem ser revistos e melhorados. O ideal é que a organização possa utilizar integralmente todo o conhecimento que dispõe, buscando transformá-lo em ferramenta de valor, principalmente, porque é nesta fase que se utiliza o conhecimento para responder às demandas do mercado. 


\section{II) PROCESSO ESTRATÉGiCO}

- AVALIAR

Para essa seção foi obtido um percentual de $\mathbf{4 1 , 3 2 \%}$, evidenciando que esta é a seção mais fragilizada de todas as que compõem o DGC. Tal resultado indica que o conhecimento e as informações existentes no SEBRAE-PB não são avaliados de forma sistemática e rotineira, o que pode acarretar um impedimento à mudança e as respostas exigidas pelo mercado, uma vez que não se tem informações sobre o que realmente é importante para a organização.

Com base na avaliação, percebe-se que a referida organização até reconhece que o conhecimento é parte da base de seus recursos da qual a organização gera valor e que a sua mensuração ajuda a entender e avaliar o desempenho organizacional geral. Porém, é desconhecido quais medidas devem ser utilizadas para monitorar e mapear o processo de gestão do conhecimento, o que dificulta a análise do capital intelectual existente e da identificação de quais conhecimentos serão necessários adquirir. Em função disso, fica inviabilizado a análise do impacto do conhecimento no desempenho organizacional.

Assim, torna-se necessário que o SEBRAE-PB incorpore no processo geral de gestão um conjunto de esquemas e medidas bem definidos que avaliem toda a base de recursos a partir das quais a organização gera valor. Para tanto, torna-se necessário que comece a perceber a seção Avaliar, como sendo uma ferramenta capaz de manter a empresa em harmonia com a realidade, bem como um caminho para implementação de estratégias mais consolidadas.

\section{- CONSTRUA/MANTENHA}

A intensidade dessa seção foi marcada por um percentual de $\mathbf{6 4 , 5 6 \%}$, indicando que a organização em análise consegue canalizar os recursos e conhecimentos disponíveis para promover a criação de novos conhecimentos. Este direcionamento poderá contribuir para que a empresa consiga assegurar que o conhecimento futuro mantenha a organização viável e competitiva, promovendo o reabastecimento, a criação e a sustentação do conhecimento. Entretanto, ressalta-se que a seção Avaliar não obteve melhores índices demonstrando que organização não conhece todo o capital intelectual disponível, assim como os que se farão necessário futuramente. Como decorrência, a construção e a manutenção do conhecimento pode não acontecer de forma viável e competitiva.

No que se refere aos relacionamentos com os colaboradores, fornecedores, clientes e comunidades nas quais operam, também são percebidos pelo SEBRAE-PB como importante instrumento para a construção de novos conhecimentos, para a criação e a manutenção do conhecimento, bem como uma alternativa de proteção de seus ativos intelectuais, apresentando os 
fluxos de informações entre eles de maneira mais livre, possibilitando que mais pessoas tenham acesso a um conhecimento importante.

De modo geral, esta seção pode ser avaliada de forma positiva, compreendendo que o SEBRAE-PB ressalta a importância dos relacionamentos para a construção e manutenção dos negócios.

\section{- DESPOJAR}

Esta seção apresentou-se com 49,21\%, um percentual considerado moderado, mas que se torna compreensível ao entender que é difícil para as organizações abandonarem as atividades e recursos que em outro momento produziram resultados valiosos.

Bukowitz e Williams (2002) destacam, entretanto, que as organizações que examinam as suas bases de conhecimento com freqüência com o objetivo de descartar o que não traz mais o retorno que anteriormente trazia, obterão mais facilmente novos conhecimentos por estarem abertos à renovação. Assim, gerenciarão melhor a enxurrada de informações disponíveis e procurarão absterem-se das desnecessárias e converter as mais relevantes em fontes de valor estratégico.

Com base nessas considerações e no percentual obtido nesta seção, recomenda-se que o SEBRAE-PB reavalie os seus repositórios de conhecimento, bem como seus ativos físicos e seja capaz de estruturar um fluxo contínuo de entrada, manutenção e saída de ativos, explorando cada etapa e considerando o que deve ser absorvido ou descartado.

A partir da análise dessas três seções, percebe-se que o processo estratégico do DGC no SEBRAE-PB necessita de algumas melhorias consideráveis, sobretudo nas seções Avalie e Despoje, as quais se apresentam com percentuais abaixo de 50\%. Percebe-se que os resultados dessas seções estão interligadas, uma vez que a baixa capacidade de avaliação do conhecimento disponível dificulta o processo de descarte do que não é mais necessário para a organização.

Em análise geral dos processos tático e estratégico, o SEBRAE-PB apresentou-se com 57,19\% o que representa uma situação mediana para o Diagnóstico de Gestão do Conhecimento, além de ter sido encontrado certa disparidade entre os percentuais obtidos entre os processos, onde o processo tático, em sua maioria, apresentou-se com percentuais bem acima dos $50 \%$. Sendo assim, existe uma série de desafios que precisam ser melhor trabalhados pela empresa em questão, como forma de atingir um nível de excelência na geração, utilização e renovação do conhecimento, proporcionando-lhe vantagem competitiva e melhor utilização dos seus recursos tangíveis e intangíveis.

\section{Considerações Finais}

A manutenção da capacidade competitiva em níveis ideais está cada vez mais condicionada a transformação do conhecimento em algo relevante e distintamente percebido pelo mercado, 
devendo ser assumida como uma sistemática prática organizacional, uma vez que pode até mesmo assegurar a sobrevivência da empresa no atual cenário dos negócios.

Neste sentido, este artigo buscou diagnosticar o processo de gestão do conhecimento no SEBRAE-PB utilizando como ferramenta o Diagnóstico de Gestão do Conhecimento proposto por Bukowitz e Williams (2002).

Por ser esse diagnóstico caracterizado por uma sucessão de etapas, onde os processos se complementam, esperava-se encontrar uma maior sincronicidade entre os processos que o constitui. Entretanto, o que se percebeu é que existe maior força no processo tático, implicando que o SEBRAE-PB utiliza melhor o conhecimento do dia-a-dia para responder às demandas imediatas do mercado e não enfatiza de forma similar o seu uso de maneira estratégica e de longo prazo.

Sendo assim, faz-se necessário uma reestruturação nas seções correspondentes ao processo estratégico, quais sejam: Avalie, Construa / Sustente, Despoje; bem como nos desafios que caracterizam cada uma dessas seções, com o objetivo maior de encontrar formas de minimizá-los ou superá-los.

Sugere-se que a organização tenha contato com o modelo utilizado neste estudo -DGC - a fim de aprofundar o conhecimento e o entendimento acerca dos processos avaliados e suas contribuições para a geração do conhecimento. Tal contato possibilitará à organização, dispor de condições e estabelecer alguns programas de ação para reverter esse quadro de desalinhamento entre os processos e assim, utilizar de forma efetiva do conhecimento existente na organização.

\section{Referências}

BUKOWITZ, W.R.; WILliaMS, R.L. Manual de Gestão do Conhecimento.Tradução Carlos Alberto Silveira Netto Soares. Porto Alegre. 2002

CALDAS, P. T. A Dinâmica de Conversão Interorganizacional do Conhecimento em Espaços Físicos, Virtuais e Mentais em uma Rede de Cooperação no Setor de Confecções. 2008. 185 fls. Dissertação (Mestrado em Engenharia de Produção) - Programa de Pós-Graduação em Engenharia de Produção, Universidade Federal da Paraíba, João Pessoa.2008.

CHOO, C. W. A organização do conhecimento: como as organizações usam a informação para criar significado, construir conhecimento e tomar decisões. Tradução Eliana Rocha. São Paulo: Senac, 2003.

DAVENPORT, T.H.; PRUSAK, L. Conhecimento empresarial: como as organizações gerenciam o seu capital intelectual. Tradução Lenke Peres. Rio de Janeiro: Campus, 1998.

EDVINSSON, L. e MALONE, M. S. Capital Intelectual: descobrindo o valor real de sua empresa pela identificação de seus valores internos. São Paulo: Makron Books do Brasil, 1998.

KRÜCKEN-PEREIRA,L.; COSTA, M. D.; BOLZAN, A. Gestão do conhecimento aplicada ao desenvolvimento de novos produtos. Revista inteligência Empresarial, Brasília, n.12, p. 48-56, jul. 2002.

LEONARD-BARTON, D. Nascentes do saber: criando e sustentando as fontes de inovação. Rio de Janeiro: Editora Fundação Getúlio Vargas, 1998.

MISKIE, R. Documentation and training: the foundation of knowledge. KM Metazine, n² 1996. 
NONAKA, I.; TAKEUCHI, H. Criação de conhecimento na empresa: como as empresas japonesas geram a dinâmica da inovação. $11^{a}$ ed. Tradução Ana Beatriz Rodrigues e Prsicilla Martins Celeste. Rio de Janeiro: Campus, 1997.

PROBST, G.; RAUB, S.; ROMHARDT, K. Gestão do Conhecimento: os elementos construtivos do sucesso. Porto Alegre: Bookman, 2002.

STEWART, Thomas A. Capital intelectual. Rio de Janeiro: Campus, 1998.

SVEIBY, K. E. A Nova Riqueza das Organizações: gerenciando e avaliando patrimônios de conhecimento. Rio de Janeiro: Campus, 1998.

TERRA, J.C.C.; Gestão do Conhecimento: o grande desafio empresarial - uma abordagem baseada no aprendizado e na criatividade. São Paulo: Negócio Editora, 2000.

TERRA, José Cláudio C. Gestão do conhecimento: o grande desafio empresarial. São Paulo: Negócio Editora, 2001.

WIIG, K.M. Knowledge Management Foundations: thinking about-how people and organizations create, represent, and use knowledge. Arlington, Texas: Schema Press, 1993.

\begin{abstract}
The complexity and uncertainty of the current environment of business organizations have required the adoption of instruments capable of generating a sustainable competitive advantage. One of these instruments involves the use of knowledge management practices from the practices of dissemination and sharing of information and knowledge. For their development and understanding, various studies have been conducted and resulted in models and methodologies specific to their development. Among the diversity of the existing models and methodologies, is that proposed by Bukowitz and Williams (2002), which refers to a model called the Diagnosis of Knowledge Management (DGC), which allows an analysis of information and of knowledge in tactical and strategic level in organizations. Accordingly, the objective of this article is to conduct an analysis of knowledge management in SEBRAE-PB from the application of the model. The research is characterized as exploratory and descriptive and was conducted as a case study. The results indicate that the organization presents the gap between tactical and strategic levels with regard to information and knowledge resources that create value for the organization.
\end{abstract}

Key-words: management, knowledge,value.

Nome completo: Ivani Costa

Filiação institucional: Centro Federal de Educação Tecnológica da Paraíba - CEFET/PB

Departamento: Programa de Pós-Graduação em Engenharia de Produção em Sistemas - PPGEPS

Função ou cargo ocupado: Professor

Endereço completo para correspondência (bairro, cidade, estado, país e CEP): Av. Maranhão, 983 -

Bairro dos Estados - CEP: 58030-261 - João Pessoa-PB

Telefones para contato: (83) 2108-1201

e-mail:ivani@sebraepb.com.br

Nome completo: Ana Cecília Feitosa de Vasconcelos

Filiação institucional: Universidade Federal da Paraíba - UFPB

Departamento: Programa de pós-graduação em Engenharia de Produção - UFPB 
Função ou cargo ocupado: Mestranda

Endereço completo para correspondência (bairro, cidade, estado, país e CEP): Rua Frei Martinho, 113 - Conceição - CEP: 58102-433 - Campina Grande - PB

Telefones para contato: (83)8825-4990

e-mail: acvasconcelos@gmail.com

Nome completo: Gesinaldo Ataíde Cândido

Filiação institucional: Universidade Federal de Campina Grande - UFCG

Departamento: Programa de pós-graduação em Recursos Naturais - UFCG e Engenharia de Produção - UFPB

Função ou cargo ocupado: Professor permanente

Endereço completo para correspondência (bairro, cidade, estado, país e CEP): Rua Esperidião Rosas, 235/703 - Tambauzinho - CEP: 58041-070 - João Pessoa-PB,

Telefones para contato: (83) 3310-1484

e-mail: gacandido@uol.com.br

Recebido para publicação em: 29/04/2009

Aceito para publicação em: 08/06/2009 